\title{
ELABORACIÓN DEL RECUERDO E IDENTIDAD EN SITUACIÓN DE VIOLENCIA POLÍTICA: NARRACIONES DE LA ETNIA ASHÁNINKA DE LA AMAZONÍA PERUANA
}

\author{
Marcela Orellana Muermann ${ }^{1}$
}

Paula Giovanetti Arancibia ${ }^{2}$

"Enterrar y callar"

(Los desastres de la Guerra,

Francisco de Goya)

\section{INTRODUCCIÓN}

Este texto indaga en la elaboración de los recuerdos sobre la violencia política en el Perú entre los años 80 y 2000, específicamente aquellos de la etnia asháninca en las riberas del río Tambo de la región de Ucayali.

El conflicto armado interno que vivió el Perú entre 1980 y 2000 constituyó el episodio de violencia más intenso, más extenso y más prolongado de toda la historia de la República. Asimismo, que fue un conflicto que reveló brechas y desencuentros profundos y dolorosos en la sociedad peruana (CVR, 2003).

Esta declaración es parte de la primera conclusión de la Comisión de Verdad y Reconciliación (CVR) del Perú, y es también el marco histórico en el que se inserta nuestro trabajo. La Comisión describe este conflicto armado como la guerra interna en la que se vieron involucrados el Partido Comunista del Perú - Sendero Luminoso (PCP-SL), el movimiento revolucionario MRTA y las fuerzas armadas, facilitada por una gran indiferencia política de la sociedad civil.

El enorme y valioso trabajo realizado por la Comisión permitió explicitar temas ineludibles para una sociedad que buscaba recomponerse después de años de violencia. $\mathrm{Su}$ afirmación de que "La CVR interpreta la voluntad del pueblo peruano de conocer su pasado" (CVR, 2003) pone de manifiesto el proceso de memoria al que el país se convocó.

Conocer su pasado supone poner en marcha el curso de los recuerdos de parte de una sociedad para conformar una memoria. No existe, sin embargo, una manera única para

\footnotetext{
${ }^{1}$ Doctora en Linguística y Filología (EHESS, París, 1985) e Professora da Universidad de Santiago de Chile.

${ }^{2}$ Magister en Literatura Latinoamericana (USACH, Chile, 2010) e Professora da Universidad de Santiago de Chile.
} 
procesar el pasado, como lo demuestra Jann Assmann (2001, p. 16) al señalar que "las sociedades forman imágenes de ellas mismas y perpetúan una identidad, más allá de las generaciones, desarrollando una cultura de la memoria; y lo hacen de acuerdo a modos muy diferentes". En una sociedad multicultural como la del Perú es dable pensar que hay más de una forma de elaborar sus recuerdos, y en el contexto antes descrito de finales del XX, parece pertinente hacerse algunas preguntas: En primer lugar: ¿Cuál es el modo o los modos en que una comunidad indígena elabora su memoria, y específicamente cómo recuerda y elabora los recuerdos de ese tiempo de violencia armada una comunidad indígena involucrada en esa violencia?

Asimismo, nos preguntamos: ¿De qué manera está ligado a una afirmación de su identidad étnica este proceso de elaboración del recuerdo? Surge aquí el tema de la finalidad que adquiere la producción de una memoria.

En este texto tratamos de responder a las interrogantes planteadas centrándonos en la etnia asháninka de la amazonia peruana, luego de realizar un trabajo de campo en comunidades de esta etnia situadas a orillas del río Tambo entre los años 2011 y 2013, específicamente en las comunidades de Cheni, Poyeni y principalmente en Betania.

En su informe final, la CVR (2003) del Perú tiene palabras para la etnia asháninka:

No existen datos precisos, pero la mayoría de especialistas e instituciones calculan
que de 55 mil Asháninkas, cerca de 10 mil Asháninkas fueron desplazados
forzosamente en los valles del Ene, Tambo y Perené, 6 mil personas fallecieron y
cerca de 5 mil personas estuvieron cautivas por PCP-SL Luminoso, y se calcula que
durante los años del conflicto desaparecieron entre 30 y 40 comunidades Asháninka.

Esta situación significó un peligro de ruptura para la etnia que vio comprometida su continuidad como grupo y también sus tradiciones ya que los canales de transmisión de conocimientos tradicionales fueron muchas veces interrumpidos por la muerte de quienes transmitían ese saber, por la separación de las familias, en fin, porque la vida cotidiana estaba centrada únicamente en la sobrevivencia.

Las comunidades que visitamos, Poyeni, Cheni y Betania fueron fuertemente convulsionadas y una de ellas, Betania, pasó a ser, en los 90, lo que se ha llamado un "núcleo poblacional", es decir una comunidad que albergó a personas desplazadas de otras comunidades de la misma etnia. Hoy en día, y como consecuencia de ello, Betania tiene una población conformada por personas provenientes de diversas comunidades ya que no todos volvieron a sus hogares una vez terminado el conflicto. 
En las entrevistas realizadas, que en un principio no estaban planificadas en torno a un tema preciso, rápidamente se impuso el tema del conflicto armado que azotó la zona entre los años 80 y 2000, definiendo entonces el tema que se transformó en una investigación, del cual forma parte este trabajo. En efecto, el conflicto armado contra Sendero fue de lo que nos hablaron personas de edades y funciones diferentes dentro de la comunidad, profesores, estudiantes, directores de la comunidad, hombres y mujeres, lo que nos fue mostrando que el tema es considerado como significativo para este grupo, y que hay una voluntad de esta de no dejarlo caer en el olvido. Por el contrario, se integran a través del recuerdo los sucesos de la guerra armada contra Sendero de manera a que sea parte de lo que son ellos hoy en día.

\section{ELABORACIÓN DEL RECUERDO}

Al ser eventos recientes, el pasado se confunde aún con el presente. La totalidad de nuestros entrevistados vivieron el conflicto en diversas circunstancias y desde distintas posiciones: algunos defendiendo su comunidad, otros siendo aún niños, varios habiendo sido desplazados, muchas mujeres manteniendo las chacras en ausencia del hombre que tradicionalmente la trabaja, y así múltiples experiencias en la que cada uno fue partícipe, de una u otra forma, de la violencia armada.

Al tratarse de un pasado reciente, a través de las entrevistas hemos sido testigos del proceso de la formación del recuerdo, una elaboración que aún está en curso. No asistimos a la reiteración de un recuerdo que es repetido de generación en generación, un saber aprendido, sino a la manera como quienes vivieron la violencia política la están formulando en narraciones. En efecto, el pasado no existe al estado natural, es una creación de la cultura donde el recuerdo se revela como un acto de semiotización en el que el pasado significativo emerge de diversas formas. Es este proceso al que las entrevistas realizadas nos ha permitido observar a través de los relatos recopilados.

\section{LAS FORMAS NARRATIVAS RECOPILADAS}

El primer año de trabajo en terreno pudimos recopilar testimonios sobre el conflicto armado contra Sendero. Muchos testimonios fueron recogidos por la Comisión de Verdad y Reconciliación en las llamadas audiencias públicas, las que y de acuerdo a Lerner (2004, p.124) fueron "espacios constituidos para que las víctimas den su testimonio y el país preste oídos. Su función es en primer lugar sanadora y reparadora”. Estas audiencias buscan, de acuerdo al Presidente de la Comisión (p. 152), "no olvidar, recuperar la memoria y acercarse a la verdad". 
Los testimonios recogidos por nosotras siguen ese patrón: buscan reflejar lo verídico de acuerdo a quien da su testimonio, y para conseguirlo, sitúan su palabra en términos de referencias posibles de comprobar, otorgando datos concretos. Una referencia fundamental es la información temporal: "en la época del terrorismo, cuando los terroristas mataron a mis padres, en el 93"3 (CECILIO, 2011).

Otro testimonio señala: "en el año 90, he visto la cosa real”. (KUMANGA, 2011). El espacio preciso otorga veracidad al testimonio: "Yo estuve en el Gran Pajonal trabajando, ¿ya?” (KUMANGA, 2011).

Otro integrante de la comunidad señala: "hemos llevado abajo, ya no había nada acá, ya hemos desplazado a Poyeni""5 (MARTIN, 2011).

La identificación de personas respecto de quien testifica hace igualmente verificable una palabra: "Hasta que una vez mi hermana, se habrá acordado de mí, y dice que me buscaba" CECILIO, 2011).

Prudencio (2011) señala:

mi mamá estaba embarazada de mi persona y bueno, yo nací el 8 de marzo (del 88) en tiempo de invierno, ya, como el invierno la quebrada que crece ¿no?... y bueno, mi mamá buscó la forma de esconderse y ahí donde he nacido y bueno dejé mi ombligo, todo... soy de la selva, netamente de la selva. ${ }^{6}$

A través de estos ejemplos, podemos constatar que el testimonio es una palabra que da cuenta de las huellas que los eventos dejaron sobre cada entrevistado (Todorov,1995) y, por lo tanto, la primera persona tiene aquí una presencia fundamental, se habla siempre e inevitablemente desde un yo.

Volvimos a las comunidades del río Tambo un año después y una tercera vez al año subsiguiente continuando con las entrevistas. Conversamos con las mismas personas y también con otras. Nos reencontramos esta vez con los testimonios, pero tuvimos también acceso a otro tipo de relato sobre el mismo contenido, que sólo se había insinuado el año anterior. Esta vez el conflicto armado nos fue relatado sin referencias espaciales ni temporales reales, sin referencias a personas específicas. La primera persona no era ya la voz que siempre enunciaba el relato, siendo generalmente reemplazada por un "nosotros", refiriéndose a la etnia asháninka. En este nuevo tipo de relato participan también, además del pueblo asháninka

\footnotetext{
${ }^{3}$ Alumno practicante de pedagogía del Centro Universitario de Nopoki, Comunidad de Cheni.

${ }^{4}$ Mikeas Kumanga es el Director de la Escuela Primaria de la Comunidad de Betania.

${ }^{5}$ Gobernador de la Comunidad de Cheni.

${ }^{6}$ Alumno practicante de pedagogía del Centro Universitario de Nopoki, Comunidad de Cheni.
} 
otros seres que tienen calidad de personajes: el río, la lluvia, algunos árboles, algunas plantas y animales.

Como ejemplos, podemos citar al río y la quebrada en la manera como ayudan a los asháninkas cuando en la comunidad de Poyeni hay un enfrentamiento con Sendero Luminoso: "sabe la quebrada, o sea es como tradición ¿no?, la quebrada sabe que va a suceder enfrentamiento, de un momento cae la lluvia y crece la quebrada ...por eso que los terrorismos no se han podido enfrentar más allá” (PRUDENCIO, 2011).

También a la hierba del piri-piri: "Y eso, por eso es, por eso los asháninkas son temibles en el gran Pajonal...ellos tienen, ya por decir, si agarran piri-piri y empieza a mascar, un ratito, empieza truenos, relámpagos información verbal”. (KUMANGA, 2012)

Tienen como te digo, piri-piri, especialmente para ellos ¿no? Cosa que cuando ellos (en este caso Sendero Luminoso) disparaban, no, no, no disparaban...o sea disparaban atrás, quebraban su armamento ¿no?, nosotros ya aprovechábamos, pues así ha sucedido... hay también piri-piri para el viento, ¿no? Cuando están ahí, de repente, ahí, están luchando, empiezan a soplar...un tremendo viento, caen palos, tremendos palos, ya, nos ayudan pe...que están ahí y se escapan ${ }^{7}$ (LUCA, 2012).

O también a un árbol: "Un árbol llamado Catahua, ya. Y ese Catahua significa que, usted, si le baleas, ya te da potencia, ya te da fuerza... para que no te haga(n) maldad" (LUCA, 2012).

El monte puede también ser protagonista: "nosotros como ashánincas nuestro monte es como si fuera nuestra madre, ¿no?, nos ayuda en todo, nos protege, nos volvemos invisibles, ¿no?” (KUMANGA, 2011).

Obtuvimos entonces dos tipos de relatos, dos elaboraciones diferentes del mismo pasado, válidas y narradas por sus cultores como verídicas y auténticas las dos. Si ya hemos clasificado una de estas como relatos testimoniales, la otra nos conduce al ámbito de lo mítico. En efecto, si recordamos las palabras de Mercia Eliade (1978, p. 13):

Los mitos describen las diversas, y a veces dramáticas irrupciones de lo sagrado (o de lo sobre natural) en el mundo. Es esta irrupción de lo sagrado que funda realmente al mundo y que lo hace ser lo que es hoy en día. Más aún, es a causa de estas intervenciones de los seres sobrenaturales que el hombre es lo que es hoy en día, un ser mortal, sexuado y cultural.

\footnotetext{
${ }^{7}$ Jefe de la Comunidad de Betania.
} 
El mismo autor (p. 14) también nos dice que "la función principal del mito es revelar las funciones ejemplares de todos los ritos y actividades humanas significativas: tanto la alimentación o el matrimonio como el trabajo, la educación el arte o la sabiduría”.

Una de las actividades significativas del hombre ampliamente representada por los relatos míticos ha sido el ámbito de lo bélico. En estos relatos que hemos clasificado de míticos, la etnia asháninka elabora el recuerdo sobre los años de violencia armada de una manera singular. Distinto del testimonio que sitúa los eventos temporal y espacialmente, posicionándolos respecto de una continuidad histórica, lejos también de una primera persona al centro de la enunciación. Por el contrario, se recuerda en estos relatos la manera como la etnia asháninka luchó y cómo esta venció a Sendero Luminoso, gracias a la irrupción de una intervención sobrenatural, explicando, más allá de las últimas décadas del XX, como lucha la etnia contra sus enemigos, sean éstos quienes sean, independientemente de la época en que esto ocurra. La presencia sobrenatural es parte del hábitat natural de la etnia, de manera que el monte, las plantas, el río, algunos animales y otros elementos de éste ayudan, como lo han hecho desde tiempos inmemoriales, al asháninka cuando éste debe oponerse a un enemigo.

\section{EL RECUERDO Y SUS FORMAS}

La constatación de la existencia de estos dos tipos de relato nos permite sostener que la etnia asháninka elabora sus recuerdos en dos órdenes: el orden de lo real, de la vida cotidiana experimentada en forma individual y el orden de lo mítico, de sentir colectivo, que proporciona una explicación simbólica a los eventos de los que habla y en el cual la dimensión histórica se desdibuja para dar paso a una sincronía en que los tiempos se confunden. En el plano de la narrativa, que es el objeto de este trabajo, estos dos órdenes se manifiestan en dos tipos de relatos de muy diferente contenido y estructura como son el testimonio y el mito.

Ahora bien, que el recuerdo pueda llegar a manifestarse bajo formas tan diferentes en contenido y estructura cuando alude a un mismo tema, plantea sin duda interrogantes acerca de las causas de estas diferencias. De la misma manera, surge la pregunta sobre el aspecto formal que puede adquirir un pensamiento, ¿es la forma del pensamiento importante además de su contenido? A este respecto, Klaus Schäffaeur y Michael (2003) hacen justamente énfasis en las configuraciones en que se manifiesta la memoria: "más allá del contenido de la memoria, el género en el cual se formula es también importante y significativo".

Volviendo a nuestro corpus de relatos, debemos entonces identificar y diferenciar en qué consiste la información que conlleva cada uno de los géneros aludidos, y que es, por 
decirlo así, previa al contenido del relato. Podremos entonces comprender de qué manera cada uno de estos géneros contribuye a "perpetuar la identidad", para retomar las palabras de Assmann citadas al principio de este artículo.

Los investigadores citados nos proporcionan nuevamente un itinerario cuando aclaran que cada forma o clase de enunciado funciona como "un contexto que permite que nuevos enunciados tengan sentido al remitirlos a otros ya existentes" (SCHÄFFAEUR y MICHAEL 2003, p. 5). En consecuencia, y en el caso del relato testimonial recopilado en tanto discurso individual y aislado, por el hecho de estar estructurado de acuerdo al género testimonio, será identificado y asociado a otros discursos anteriores de similares características. Alcanzará así una densidad nueva ya que se sumará a otras voces anteriores, adquiriendo una validez colectiva y pasará, por ello, a ser parte de la identidad de la comunidad.

Por su parte, en el caso de los relatos sobrenaturales, su integración al acervo mítico de la etnia asháninka posibilita vincular estos relatos, más allá de su enfrentamiento con Sendero Luminoso, a sus creencias ancestrales. Esta calidad les otorga una autoridad entre quienes componen la etnia que trasciende un momento particular y los vincula a la memoria cultural de este grupo humano.

\section{CONCLUSIÓN: ELABORACIÓN DEL RECUERDO E IDENTIDAD}

Para concluir estableciendo la relación entre la elaboración del recuerdo y la identidad de la etnia asháninka, se requiere por último revelar el vínculo entre los recuerdos del pasado y el lugar que el pasado tiene en el presente. Es hoy en día cuando estos recuerdos de la violencia política que asoló a la etnia asháninka en su lucha contra Sendero Luminoso están siendo elaborados a fin de construir una memoria cultural; y en este contexto, las palabras de Schaffeur y Michael (2003) adquieren relevancia: "la memoria consiste en la selección y construcción de contenidos recuperados del pasado que satisfacen la demanda identitaria del presente."

El recuerdo del pasado nunca es, por lo tanto, un recuerdo por sí mismo, el relato de ese recuerdo tiene una función dictada por el presente para respaldar y proteger la identificación del grupo.

La elaboración del pasado reciente por la etnia asháninka distingue entre el testimonio y el mito otorgándoles a cada uno un lugar en la memoria cultural que van construyendo. En el caso del testimonio, las palabras de Salomón Lerner son clarificadoras; este permite a un individuo traumatizado y fragmentado por sus vivencias, volver a formar parte de una colectividad que ha experimentado lo mismo que él y en ese sentido construir y narrar su 
testimonio es una experiencia integradora al mismo tiempo que sanadora. En este sentido, construir y narrar su testimonio es una experiencia integradora al mismo tiempo que sanadora, lo que permite al asháninka continuar en la construcción del presente sin olvidar la propia historia. Por esta razón, en sus relatos conviven dos tiempos identificables: el histórico y el mítico, que cobra un cariz de infinitud. En palabras de Eliade:

Lo importante no es siempre renunciar a la situación histórica, esforzándose en vano por alcanzar el Ser Universal, sino conservar constantemente en el espíritu la perspectiva del Gran Tiempo, mientras en el tiempo histórico se continúa realizando el propio deber (ELIADE, 1956).

En efecto, a través de la experiencia vivida en las visitas y entrevistas, vemos cómo la mitificación de la historia de la propia resistencia da sentido al presente de la comunidad; entrega valor al rol de la naturaleza, la ascendencia étnica, el entorno y la organización defensiva de carácter militar que continúan hasta el presente. El asháninka tiene una larga historia de resistencia al invasor, haya sido este el español de la época Colonial, el cauchero de fines del XIX y primeras décadas del XX, el colono que se instala en sus tierras, ayer Sendero Luminoso. Cada vez el asháninka ha combatido de acuerdo a sus creencias ancestrales, reforzando una identidad como etnia y, que hace decir a Mikeas Kumanga, director de la escuela primaria de la comunidad de Betania: "por eso es que los asháninkas son temibles en el Gran Pajonal".

\section{REFERENCIAS}

ASSMANN, J. La mémoire culturelle. Ecriture, souvenir et imaginaire politique dans les civilization santiques. Paris: Editions Flammarion, 2010.

CECILIO. Entrevista concedida a M. Orellana y P. Giovanetti. Atalaya, 2011. Grabación digital para proyecto Fondecyt, n.1130739 "Oralidad: testimonio y memoria en Amazonía.

COMISIÓN VERDAD Y RECONCILIACIÓN. Informe Final. http://cverdad.org.pe/ifinal/. Recuperado el 10 de mayo de 2015

ELIADE, M. Mito y Realidad. Guadarrama, Barcelona: Guadamarra, 1978.

ELIADE, M. Imágenes y símbolos: ensayos sobre el simbolismo mágico-religioso. Madrid:Taurus, 1956.

KLAUS SHÄFFAUER, M.; MICHEL, J. Géneros entre medios y memoria: pasajes cronotípicos. Disponible en: https://goo.gl/Cdf0sh. Recuperado el 10 de mayo de 2015.

KUMANGA, M. Entrevista concedida a M. Orellana y P. Giovanetti. Atalaya, 2011. Grabación digital para proyecto Fondecyt, n.1130739 "Oralidad: testimonio y memoria en Amazonía".

KUMANGA, M. Entrevista concedida a M. Orellana y P. Giovanetti. Atalaya, 2012. Grabación digital para proyecto Fondecyt, n.1130739 "Oralidad: testimonio y memoria en Amazonía". 
LUCA, E. Entrevista concedida a M. Orellana y P. Giovanetti. Atalaya, 2012. Grabación digital para proyecto Fondecyt, n.1130739 "Oralidad: testimonio y memoria en Amazonía".

LERNER, S. La rebelión de la memoria: selección de discursos. Disponible en: https://goo.gl/Sjgkss. Recuperado el: 10 de mayo de 2015.

MARTIN. Entrevista concedida a M. Orellana y P. Giovanetti. Atalaya, 2011. Grabación digital para proyecto Fondecyt, n.1130739 "Oralidad: testimonio y memoria en Amazonía".

PRUDENCIO. Entrevista concedida a M. Orellana y P. Giovanetti. Atalaya, 2011. Grabación digital para proyecto Fondecyt, n.1130739 "Oralidad: testimonio y memoria en Amazonía".

TODOROV, T. La mémoire devant l'Histoire. Disponible en: https://goo.gl/keQvwT. Recuperado el 10 de mayo de 2015. 